Chapter 4

\title{
Combining Moderate-Resolution Time-Series RS Data from SAR and Optical Sources for Rice Crop Characterisation: Examples from Bangladesh
}

\author{
Andrew Nelson, Mirco Boschetti, Giacinto Manfron, \\ Franceco Holecz, Francesco Collivignarelli, \\ Luca Gatti, Massimo Barbieri, Lorena Villano, \\ Parvesh Chandna and Tri Setiyono
}

Additional information is available at the end of the chapter

http://dx.doi.org/10.5772/57443

\section{Introduction}

Operational monitoring of agricultural extent and production is part of several national and international efforts to provide transparent, rapid and accurate information related to food security and food markets. Initiatives such as the G20 Agricultural Market Information System (AMIS), the European Commission's Monitoring Agricultural Resources mission (MARS), the Global Agricultural Monitoring (GEOGLAM) component of GEO, and the United States Department of Agriculture's Global Agricultural Monitoring Foreign Agricultural Service (GLAMFAS), are just some examples of operational services that do, or will require remotesensing-based information on crop status in almost any part of the world.

Of the thousands of edible plants, just three-rice, wheat, and maize - provide $60 \%$ of the global population's food energy intake, and the top 15 crops amount to $90 \%$ [1]. Seasonal or monthly estimates of production and availability of these staples form a part of many agricultural bulletins and agricultural outlook reports. These reports are used for decision-making and policies on imports, exports, subsidies, and investments, which, in turn, affect prices. Food security is fundamentally about availability and price; such reports, and the responses to these reports, affect both. International events, such as the food price crisis of 2008, are the unintended outcome of national and international policy decisions that can detrimentally affect 
millions of people. More accurate and timely information to better inform policymakers is one way to reduce the likelihood of similar events in the future.

Crop bulletins and other regular assessments of crop area and production are a combination of statistics, surveys, reports from agricultural offices, Met Office forecasts, expert opinion, and remote-sensing information on vegetation, soil moisture, and rainfall. However, there is scope to increase the role of remote sensing in these reports if the information can be provided at the appropriate time, scale, and, wherever possible, with a focus on specific crops. Highly anticipated programmes such as the European Space Agency's (ESA) Sentinel constellation can provide exactly this type of information, although the demands for sustainably acquiring, processing, validating, and delivering the information are considerable.

This chapter provides a proof of concept for how a key staple crop can be monitored on a national scale using existing remote-sensing (RS) products that will soon be complemented and superseded by forthcoming sensors. Our exemplar crop is rice and our test country is Bangladesh (Figure 1). This region is highly suitable for a demonstration because of the triple remote-sensing challenge of pervasive cloud cover, small field size, and complex cropping patterns, which are typical of the vast and important agricultural areas of Asia, Africa, and Latin America. It is these areas where future gains in productivity must and will be made, not the agricultural areas of Europe, the US, and other developed regions where crop monitoring is substantially easier.

We first briefly describe the rice environments of Bangladesh, and then demonstrate how a combination of hypertemporal synthetic-aperture radar (SAR) and optical RS data can be combined to generate both baseline map information and near-real-time monitoring information on crop extent and crop seasonality.

\section{Rice in Bangladesh}

Agriculture is one of the most important sectors in Bangladesh's economy, accounting for approximately $20 \%$ of the gross domestic product (GDP) in 2010. It also accounts for the employment of over $60 \%$ of the country's population [2]. Rice is far and away the most important crop in the agricultural sector. Almost $60 \%$ of the land area is planted to rice and it provides food, employment, and income for much of the rural population. Bangladesh is one of the most populous countries in Asia, with almost 150 million people, according to the 2011 census. With over 1,000 people per square kilometre, it is one of the most densely populated countries in the world [2]. The country's milled rice consumption per capita is the highest in the world at $173 \mathrm{~kg}$ per year or almost $500 \mathrm{~g}$ of uncooked rice per day [1].

Rice can be cultivated in any of three seasons in Bangladesh in a myriad of cropping systems such as rice/pulse, rice/maize, rice/wheat, rice/vegetables, rice/shrimp and double-or triplerice monoculture. The dry boro season, which runs from November to April, is largely dependent on irrigation and is of growing importance to Bangladesh's rice output. This is followed by the aus season (sometimes referred to as early kharif), which runs from March to 


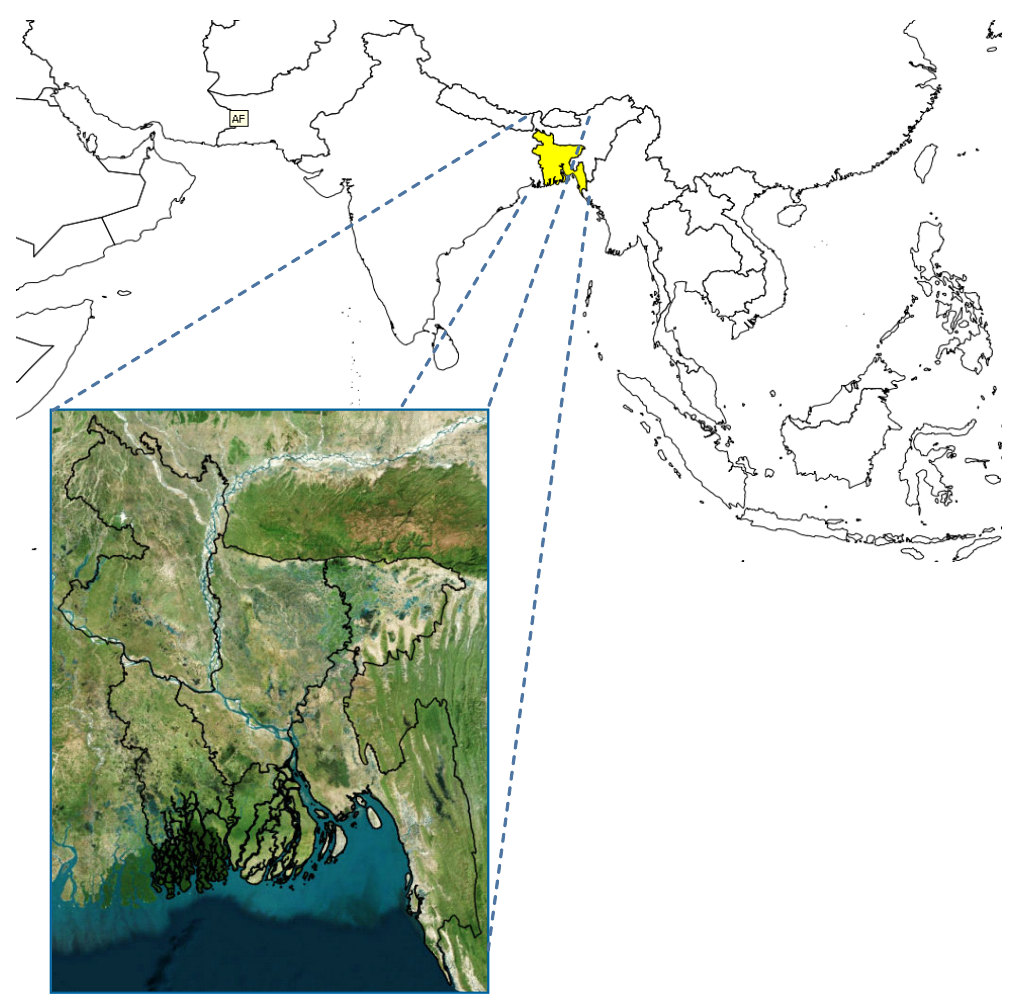

Figure 1. Location of Bangladesh in Asia.

August and relies on irrigation to establish the crop and early monsoon rains during the rest of the season. The aman season from June to December relies almost entirely on monsoon rains and is another major source of rice production. Deepwater aman rice grown in flooded conditions using tall varieties or floating rice starts in April or May, but is harvested in November/December. Figure 2 shows how these seasons overlap due to the large variation in (trans)planting and harvesting windows across the country. In general, the boro season starts in the east and south and moves northward; whereas, the rainfed aman season starts in the northernmost reaches of the delta and moves from north to south, although, local conditions, cropping patterns, and other management decisions can affect this trend.

Figure 3 shows the trends in rice cropped area per season for 1999-2012 and Figure 4 shows the reported area for each of the 64 districts in 2011 based on BBS annual reports [2-3]. Figure 3 shows the general stability in total rice area with extremes of 10.4 (2004) and 11.5 (2011) million hectares; the recent increases are mainly due to the expansion of the area in the boro season. Figure 4 shows the general spatial distribution of rice per season where the boro crop is mainly in the north and east, the much smaller aus crop area is in various clusters across the country, and the aman crop is dominant in both north and southern coastal regions. 




Figure 2. Generic rice crop calendar for Bangladesh (from FAO).

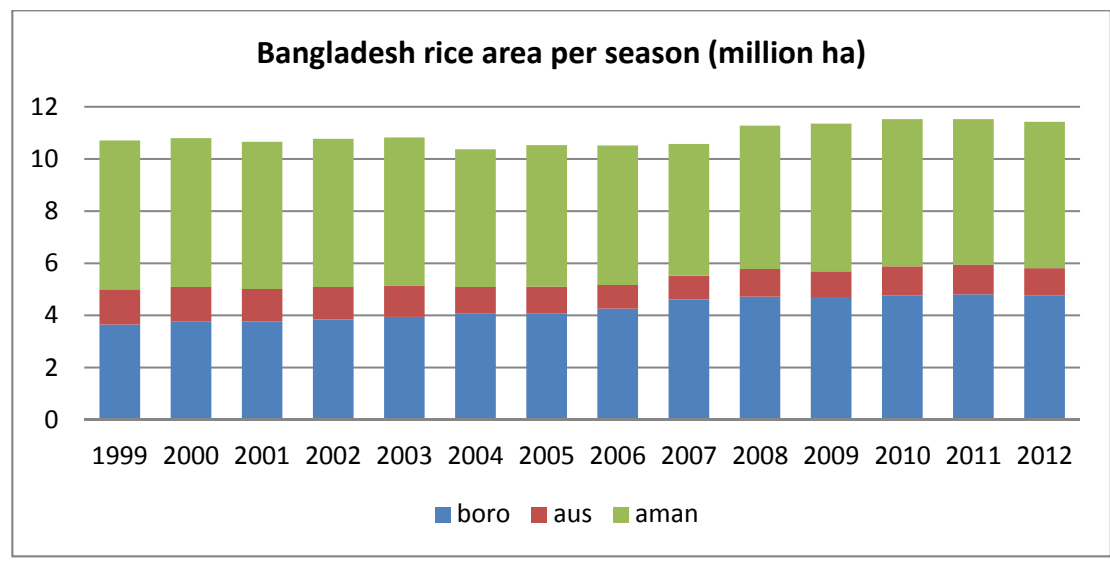

Figure 3. Bangladesh rice area by season 1999-2012 (Source: [2-3]).

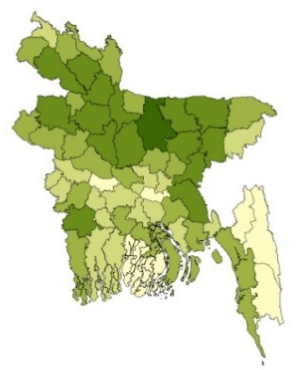

0

$1-25000$

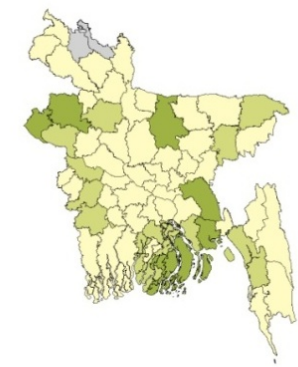

Rice ha per season (2011)



$100000-200000$ $200000-300000$

$0 \quad 100200300$ Kilometers

Figure 4. Bangladesh rice area per district in 2011 (I to r: boro, aus, aman) (Source: [3]). 
Whilst production has increased steadily over the past 10 years, this trend faces multiple challenges. Flooding from excessive rainfall and the massive inflow from the Ganges (called Padma in Bangladesh), Brahmaputra (called Jamuna in Bangladesh), and Meghna rivers is estimated to severely affect 1.32 million ha and moderately affect a further 5.05 million ha. Crop losses from such massive inundation can be enormous. At the same time, drought brought on by a shortage of rainfall affects both the rainfed aman crop and the dry season crops, with a total drought-affected area estimated at 3.52 million ha. Salinity and tidal surges from cyclones affect a further 1 million ha of cultivated land, and any given area can suffer from one or more of these stresses during the year [4]. Severe yield losses are also attributed to pests, diseases, weeds, and other biotic yield reducers.

The possible impacts, both positive and negative, of changes in climate, society, economy and technology are hard to quantify, but the fundamental message is that Bangladesh faces multiple challenges to food production which are the focus of ongoing research and development across the country, such as stress tolerant varieties, innovative cropping systems, investments in infrastructure, extension and training. Bangladesh has been identified as one the countries with the highest vulnerability to anticipated climate change and there is continued need to deliver the best possible crop status information to policy makers as a contribution to sustainable and resilient agricultural production.

In summary, rice can be cultivated during any month and it faces different pressures in each of the three seasons. Rice is cultivated in varying amounts in every district with differing spatial patterns each season. Thus any RS-based monitoring requires frequent observations throughout the year across the entire country. For this reason, hypertemporal imagery with a large footprint, such as MODIS and ENVISAT WS products, are good choices for baseline rice extent mapping and rice seasonality monitoring. They also serve as a proof of concept of what can be achieved at higher spatial and temporal resolutions with future satellite programmes in an operational monitoring context.

\section{Methods and data}

\subsection{Multi-temporal SAR and optical data for rice mapping and monitoring}

Field conditions and crop evolution follow well understood seasonal changes, which can be observed by multi-temporal remote-sensing data. Combined with a priori knowledge of the crop calendar and land practices, this multi-temporal remote-sensing data can be correctly interpreted to deliver valuable information. For rice, at the start of the season, remote-sensing time-series can determine when and where fields are prepared and irrigated. The same timeseries information can also capture the various crop stages, starting from seeding or transplanting and then through the vegetative, reproductive, and ripening stages until harvest. In synthesis, assuming that images are regularly acquired, the key source of information about crop presence and status is the temporal signature [5-9]. Systematic acquisitions are essential; one image or randomly acquired scenes, even with very high resolution, are of limited use for crop monitoring. 
SAR systems have a proven ability to detect irrigated and lowland rice through the unique backscatter temporal signature. In the past three decades, a significant number of publications have been dedicated to the rice signature and to its detection and monitoring [10-17]. In summary, these studies have shown that:

- Lower frequencies (L-and C-band) penetrate deeper into the rice plant than higher frequencies, whereas higher frequencies $(X-b a n d)$ interact better with rice grains.

- Double bounce dominates at L-band, whereas volume scattering prevails at X-band.

- The correlation between the backscattering coefficient and rice bio-physical parameters shows that, lower frequencies are more related to the total fresh weight, leaf area index, and plant height; whereas higher frequencies better correlate with grain weight and grain water content.

- The date of the maximum backscattering coefficient at X-band precedes those of C-and Lband.

- The VV backscattering coefficient increases only during the vegetative stage; it is quite stable at the reproductive stage, and it decreases at the ripening stage due to the canopy attenuation.

- The HH backscattering coefficient increases at the reproductive stage, and it is quite stable at the ripening stage. The temporal trend of the HV backscattering coefficient is similar to the $\mathrm{HH}$ one.

- The VV/HH polarization ratio, at C-and L-band, significantly decreases throughout the course of the crop season, hence proving its sensitivity to rice plant age.

- The frequency ratios for HH and VV (C-VV/L-VV and C-HH/L-HH) are significantly lower in the latter part of the rice season, when thick vegetation canopy hampers wave penetration.

High-resolution optical images in the tropics are strongly limited for crop monitoring purposes, especially rice. Most rice is grown in the rainy or monsoon season and images often suffer from persistent and widespread cloud contamination. High-resolution images are rarely available with high temporal frequency, so gap-filling and smoothing options are limited. On the contrary, moderate-resolution systems with daily revisiting cycles, such as MODIS, have the appropriate spectral bands and temporal resolution needed for crop identification and phenological monitoring at regional scales.

Although sometimes neglected and rarely the subject of discussion in remote-sensing literature, the impact of meteorological conditions and crop practices on rice plant growth is often significant. Some prior knowledge of the rice variety, the crop calendar, varietal maturity, crop management practices for water and inputs, and meteorological conditions is prerequisite for the correct interpretation of the temporal signature and for the generation of an accurate 'rice map', whatever the specific information (i.e., rice area, start of season date, etc.) in the map. This agronomic and meteorological information must be considered in the development of a rice detection algorithm. 
Thus, there is an opportunity to use both SAR and optical time-series information for rice crop detection and monitoring, provided that there is sufficient a priori knowledge of the rice system under observation. The following approach is based on specific peculiarities and complementarities of high temporal resolution and moderate spatial resolution SAR and optical data; however, the approach can also use higher resolution imagery if available.

Given the higher spatial resolution but limited revisiting time (ranging from 16 to 24 days), SAR data are primarily used to estimate the spatial extent (resolution $100 \mathrm{~m}$ ) of the rice crop. Medium-resolution optical data with a quasi-daily revisiting cycle are used to derive the land surface phenology as a means to identify key stages of the rice crop season. There are two distinct processing chains to develop rice monitoring products on an operational basis: one for the rice extent/area estimation from SAR, another for rice seasonal monitoring within that extent/area from MODIS. The main advantages of this approach are:

- It overcomes the spatial-temporal problem, hence, assuring an appropriate temporal repetition at an adequate scale (i.e., spatial resolution) even over large areas;

- It provides an operational monitoring system, which is based on multi-sensor data redundancy.

Figure 5 illustrates the overall approach. Depending upon data availability, rice products based on archive and actual remote-sensing data at different spatial scales can be generated. Here, we will discuss the use of archive ENVISAT ASAR Wide Swath data (100 m) and MODIS $(500 \mathrm{~m})$, leading to a multi-year rice extent and phenological monitoring product.

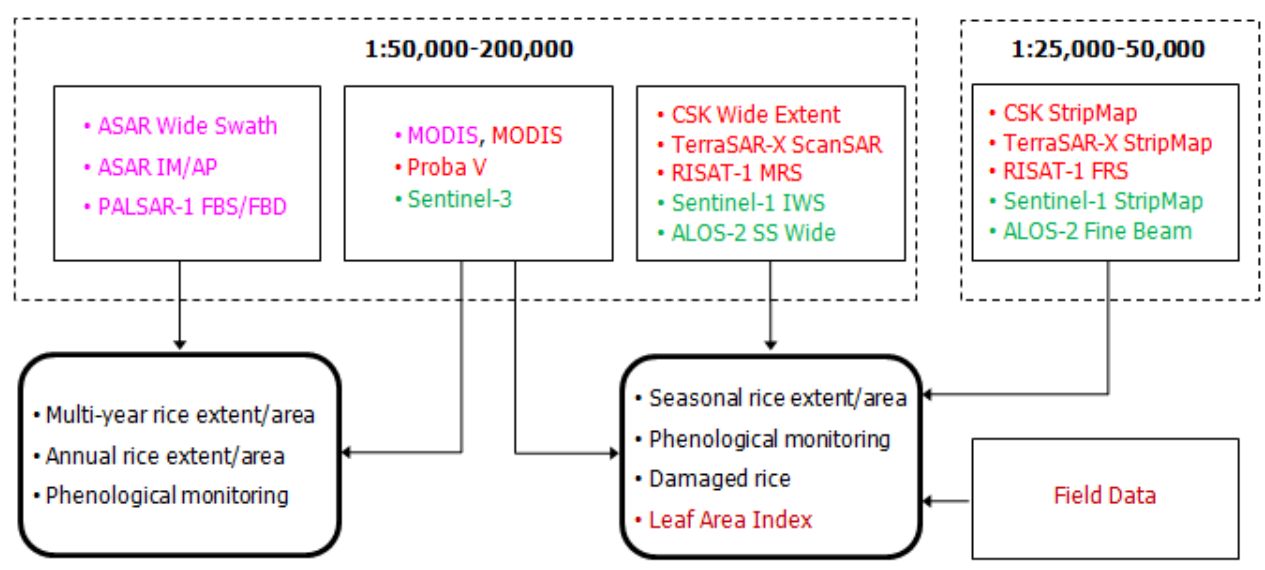

Figure 5. Products and supported sensors (past, current, near future) including acquisition modes. 


\subsection{Multi-year rice extent from archive ENVISAT ASAR Wide Swath data}

The C-band Advanced Synthetic Aperture Radar (ASAR) on board of the ENVISAT satellite ensured continuity of the ERS-1/2 SAR systems between 2002 and 2012. It featured enhanced capability in terms of coverage, range of incidence angles, polarisation, and modes of operation. There were three ASAR acquisition modes with a 35-day repeat cycle:

- Wide Swath mode-WS (400 by $400 \mathrm{~km}, 100 \mathrm{~m}$ resolution, HH or VV),

- Image mode - IM (100 by $100 \mathrm{~km}, 15-25 \mathrm{~m}$ resolution, HH or VV), and,

- Alternating Polarization - AP (100 by 100 km, 15-25 m resolution, HH/VV or HH/HV or VV/ $\mathrm{VH})$.

The 10-year ENVISAT ASAR WS data archive is mainly based on background mission acquisitions, hence, it was not specifically planned and not optimised for agricultural applications. Nevertheless, the large archive can be exploited for rice mapping with appropriate processing and interpretation. A fully automated processing chain has been developed to convert the images into terrain geocoded backscattering coefficient $\left(\sigma^{\circ}\right)$.

1. Co-registration - Images acquired with the same observation geometry and mode are coregistered in slant range geometry. This step is mandatory to allow time-series speckle filtering.

2. Time-series speckle filtering - An optimum multi-temporal filtering is used to balance differences in reflectivity between images at different times [18]. Multi-temporal filtering is based on the assumption that the same resolution element on the ground is illuminated by the radar beam in the same way, and corresponds to the same slant range coordinates in all images of the time series. The reflectivity can change from one time to the next due to a change in the dielectric and geometrical properties of the elementary scatters, but should not change due to a different position of the resolution element with respect to the radar.

3. Terrain geocoding, radiometric calibration, and normalization - A backward solution by considering a Digital Elevation Model is used to convert the positions of the backscatter elements into slant range image coordinates. A range-Doppler approach is used to tranform the three-dimensional object coordinates in a cartographic reference system into the two-dimensional row and column coordinates of the slant range image. During this step, the radiometric calibration is performed by means of the radar equation, where scattering area, antenna gain patterns, and range spread loss are considered. Finally, the backscattering coefficient is normalized according to the cosine law of the incidence angle in order to compensate for the range dependency.

4. Anisotropic Non-Linear Diffusion Filtering - This filter significantly smoothes homogeneous targets, whilst also enhancing the difference between neighbouring areas. The filter uses the diffusion equation, where the diffusion coefficient, instead of being a constant scalar, is a function of image position and assumes a tensor value [19]. In this way, it is locally adapted to be anisotropic close to linear structures such as edges or lines. 
5. Removal of atmospheric attenuation - Although microwave signals have the ability to penetrate through the clouds, it is possible, particularly at short (X-and C-band) wavelengths, that severe localised storms can affect the backscattering coefficient in the range of several $\mathrm{dB}$. The temporal signature of the backscatter coefficient can be affected in two ways: (1) the thick layer of water vapor generates a strong decrease of backscattering coefficient, followed by a strong increase; (2) the strong rainfall generates a strong increase of the backscattering coefficient, followed by a strong decrease. These effects are corrected in the processing chain by analyzing the temporal signature-anomalous peaks or troughs are identified and the backscattering coefficient values are corrected by means of an interpolator. This correct application of this process relies strongly on a priori knowledge of the rice system and the weather conditions when the image was acquired.

Once the WS archive has been processed, it is ready for interpretation. Rice detection relies on interpretation of the temporal signature from regular acquisitions within a given year or season. The 2002-2012 WS archive does not have regular acquisitions over any one area and so, we made the following assumption. Given that rice extent in Asia is relatively constant (see Figure 3 for evidence of this in Bangladesh) and cropping calendars are relatively stable, we can then develop a pseudo-annual time-series with a relatively high temporal occurrence by combining all years of WS observations into one year. This is illustrated in Figure 6 where the multi-year SAR data for a selected time frame (e.g., weekly, bi-monthly) is temporally averaged leading to an annual signature.

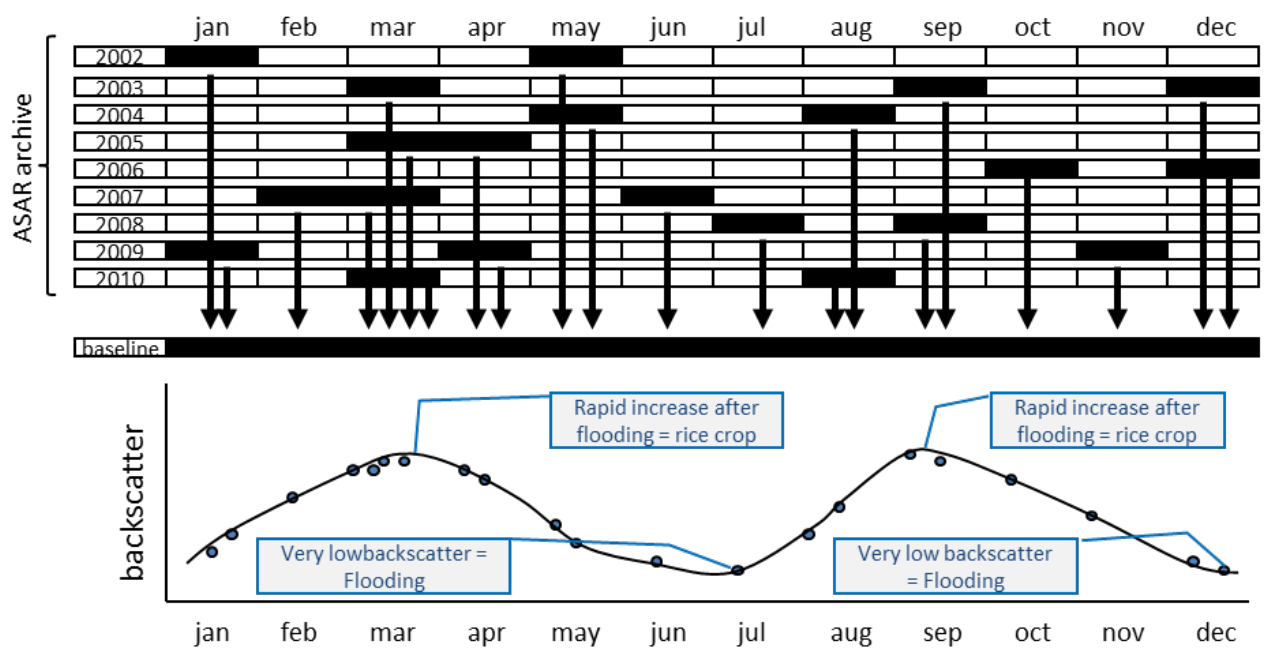

Figure 6. Example of the pseudo-annual time series for a single pixel based on multi-year ASAR Wide Swath data (2002-2010).

This temporal signature can be interpreted in two ways: 
1. The temporal evolution of the backscattering coefficient is analyzed from an agronomic perspective. This assumes that the data have been regularly acquired in temporal terms, and that a priori knowledge of rice type, calendar and duration, crop practice, and meteorological conditions during the whole season is available. This is not the case for the WS archive, so we move to option two.

2. From the backscattering coefficient time series, representative temporal features (or descriptors) can be derived. Even if this approach cannot derive specific information on the rice phenology [9], it can provide valuable information on the rice location and, depending upon the temporal frequency of the SAR acquisitions, the various rice seasons. We use this approach for interpreting the signature from the WS archive.

The most representative temporal features for rice have been found to be the relative minimum and maximum, their difference, and minimum and maximum increment between two subsequent acquisitions. The selected five temporal features are used to generate rice extent and rice seasons according to:

1. The start of the rice season is identified when there is a relative minimum followed by a maximum increment between two subsequent acquisitions;

2. The peak of the rice season is identified when there is a relative maximum followed by a minimum increment between two subsequent acquisitions;

3. The pixel is classified as rice if:

- conditions 1 and 2 are satisfied;

- the range between relative minimum and maximum attains a minimum value;

- the temporal duration between 1 and 2 is within a given duration;

4. Rice is further distinguished in single, double, triple, etc., according the number of valid minima and maxima (condition 3).

\subsection{Phenological monitoring with MODIS data}

\subsubsection{MODIS data for land surface monitoring}

With the launch of the Moderate Resolution Imaging Spectroradiometer (MODIS), onboard the NASA TERRA (EOS AM-1) satellite, a new era in multi-spectral satellite remote sensing began. MODIS sensors permit continuous monitoring of the environment by measuring spectral bands from the blue to the thermal infrared. The 36-band MODIS spectrometer provides a global data set every 1-2 days. The swath dimensions of MODIS are 2,330 × 2,330 $\mathrm{km}$ and the spatial resolution (pixel size at nadir) is $250 \mathrm{~m}$ for channels 1 and $2(0.6 \mu \mathrm{m}-0.9$ $\mu \mathrm{m}), 500 \mathrm{~m}$ for channels 3 to $7(0.4 \mu \mathrm{m}-2.1 \mu \mathrm{m})$ and 1,000 $\mathrm{m}$ for channels 8 to $36(0.4 \mu \mathrm{m}-14.4$ $\mu \mathrm{m})$.

There are many standard MODIS data products that are provided to users in near-real-time and easy-to-use formats for no cost. The MOD09A1 product (a full technical description is 
available online at https://lpdaac.usgs.gov/products/modis_products_table/mod09a1) provides 8-day composite reflectance data across seven spectral bands (red-0.6 $\mu \mathrm{m}$, NIR-0.9 $\mu \mathrm{m}$,

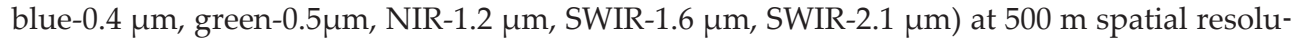
tion, as well as pixel-specific quality control flags and observation dates. This product type is derived from a multi-step process that considers atmospheric, cloud, and aerosol corrections, and records the best reflectance data registered during the time composite window for each pixel. MODIS product data are provided in Hierarchical Data Format (HDF) on a tile system with the Sinusoidal projection grid. Each tile of the grid covers an area of 1,200 $\times 1,200 \mathrm{~km}$, more or less $10^{\circ}$ of latitude and longitude (Figure 7A). Despite drawbacks related to spatial and spectral resolution, it is the zero cost, ease of access, clarity of product description, and ready-to-use nature of MODIS products that have contributed to their widespread use as a source of remote-sensing information for monitoring.

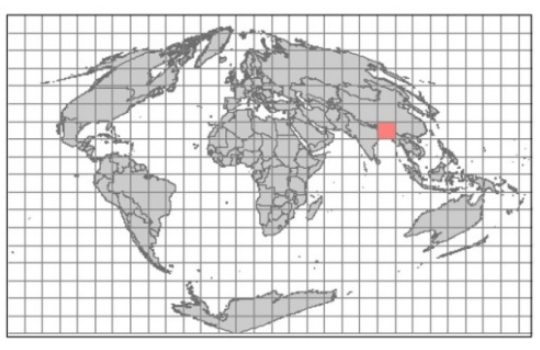

A)
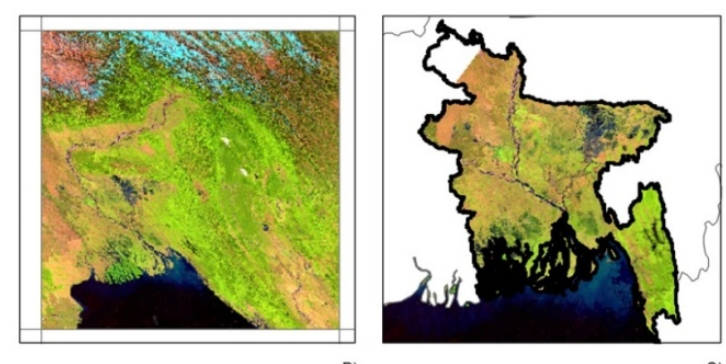

B)
C)

Figure 7. The study area: The location of MODIS tile H26V06 in the Global Sinusoidal projection map (A), tile H26V06 which covers most of Bangladesh (B), and, Bangladesh in geographic coordinates showing the extent of H26V06, which covers all the country except the far the north west (C).

\subsubsection{PhenoRice algorithm}

MOD09A1 data for 2011 from the tile H26V06 (Figure 7B) were used to demonstrate seasonal rice monitoring in Bangladesh (Figure 7C) using a rule-based automatic algorithm called "PhenoRice." The aim of the PhenoRice approach is to detect paddy rice by analysing multispectral data with quasi-daily revisiting cycles (e.g., TERRA/AQUA-MODIS, SPOT-VGT, etc.) in a consistent and flexible way that minimises dependency on local threshold adaptation.

The basis for this approach is described in previous publications by CNR-IREA [7,20,21]. Before any seasonal phenological monitoring can be performed, PhenoRice needs an estimate of the rice-growing area. If there is no rice extent map available, then the PhenoRice process relies on the work of [6,22-23] which identifies irrigated or lowland rainfed rice when a clear and unambiguous agronomic flood is detected and is shortly followed by a rapid increase in vegetation growth. However, the process can also use available land cover maps that show rice extent, or use multi-year rice extent maps such as in this case study. The seasonal phenological monitoring part of PhenoRice is performed by analysing the temporal signatures of various vegetation indices [20]. 
Figure 8 shows a schematic diagram illustrating the concept and steps of PhenoRice algorithm. The algorithm involves three fundamental processing steps.

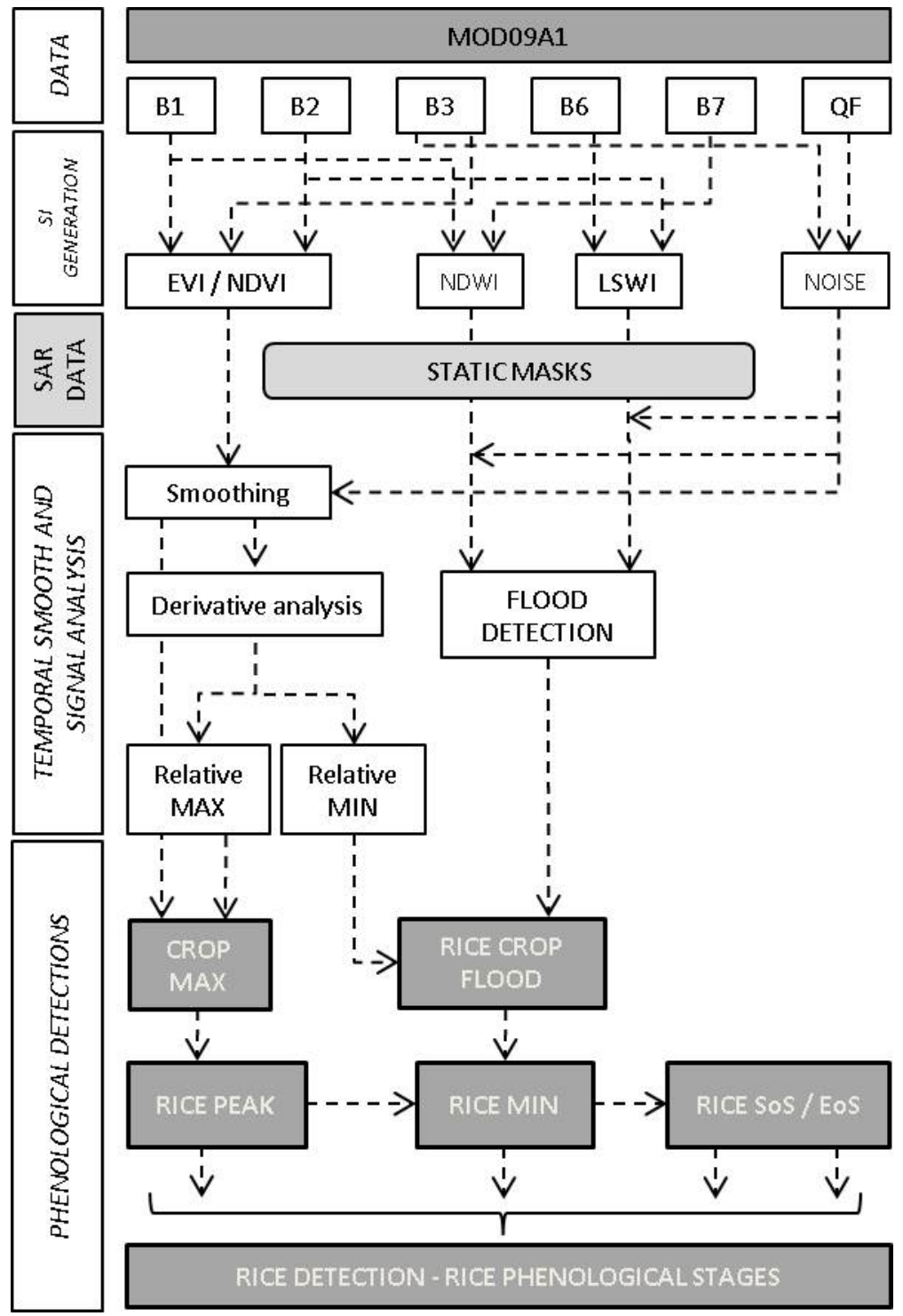

Figure 8. PhenoRice flow chart.

1. Pre-processing of MODIS composite data 
a. The identification of noise in the data by analysing the MODIS Science Data Set (SDS) cloud and snow quality flags and blue band reflectance values. Quality flag values are extracted from HDF layer 11 (500 m State Flag): bits 0-1, 3-5, and 15 are analysed to identify cloud, land, and snow noises, respectively. This information, together with a threshold on the blue band, is then combined to evaluate noise in the spectral data and error in the computed spectral indices.

b. The computation of time series of spectral indices (SI) to perform (1) flood detection, using moisture [Land Water Surface Index, LWSI [22]] and water [Normalized Difference Water Index, NDWI [24]] indices, and (2) vegetation growth monitoring using the Enhanced Vegetation Index, EVI [25]. The red (layer 1), NIR (layer 2), blue (layer 3), and SWIR (layer 7) bands are extracted from each HDF file to compute the EVI, LSWI, and NDWI indices.

2. Smoothing and temporal signal analysis

a. The EVI time-series is smoothed in order to reduce contamination that still affects the MODIS data after the temporal compositing procedure. In the smoothing process, the raw EVI profile is analysed to detect and clean outlier values, i.e., anomalous peaks and irregular small drops. Finally, a temporal smoothing on the EVI data is applied using a local polynomial function that weighs observation in relation to cloud contamination (output of step 1a), which is based on a Savitzky-Golay filter [26]. This filter is specifically recommended for the interpolation of vegetation index timeseries.

b. Derivative analysis: The smoothed signal is then analysed in order to calculate the first derivative. These derivatives are used to automatically identify all points of local (relative) minima (where the first derivative changes from negative to positive) and local (relative) maxima (where the first derivative changes from positive to negative).

3. Rice and phenological detection

a. Rice transplanting/seeding (MIN point) is identified when a local EVI minima occurs at the same time as a flood (NDWI, LSWI), and a series of positive EVI derivative values (indicating plant growth) occur shortly after.

b. Rice heading/flowering (MAX point) is detected when there is a local absolute maxima in the EVI time-series.

c. Finally, following [7], the smoothed EVI signal is analysed to extract rice emergence [start of season (SoS)] and maturity [end of season (EoS)]. These metrics are identified for each rice pixel, when EVI values match pixel-specific relative thresholds.

All the PhenoRice outputs refer to a temporal window of 12 months from 1 January to 31 December with a temporal step of 8 days corresponding to a MODIS composite granularity. For the year under analysis, referred to as Current Year (CY), the method is able to provide information on the different rice crop seasons (up to three) that occur in the period. It is 
assumed that a rice season belongs to the given $\mathrm{CY}$, if at least the maximum (i.e., heading) of the crop occurs in this period (from January to December).

In order to provide a flexible method able to detect rice seasons in different environmental and climatic conditions with a specific crop calendar, we assume that the start of the season (flooding and seeding/transplanting) can occur in the previous calendar year (PY) up to six months before the start of $\mathrm{CY}$. This results in an 18-month analysis period, which corresponds to 24 8-day MOD09A1 composites (192 days) in the PY and 46 8-day composites in the CY under analysis.

Finally, phenological metrics maps are produced for each quarter of the year. A rice detection is therefore attributed to the quarter, in which heading occurs. Consequently, the associated MIN, SoS, and EoS detection are referred to the same quarter, but as separate maps. In the case study of Bangladesh, output maps have been post-processed and synthesized for the specific cropping seasons of the country. Following the knowledge of the local crop calendar, all the detection that occurs between February and late April are attributed to boro, the ones between May and late July to aus, and others in the period from August to late November to aman.

\section{Results}

\subsection{Multi-year rice extent from the ENVISAT WS archive}

The 2002-2010 ASAR Wide Swath data stack consists of around 340 frames. Four scenes (in two different orbits) were needed to completely cover the country. Hence, on average, there are 85 frames across the 8 -year period, corresponding to around 10 images per month in the pseudo-annual time-series approach (Figure 6). In practice, the amount of images per month in the pseudo-annual stack varies between 3 and 16, meaning that the archive data is not suitable for annual or regular monitoring purposes. Figure 9A illustrates the country coverage mosaic of three temporal features: the relative minimum, the relative maximum, and the maximum variation.

The three temporal features, illustrated as a mosaic in Figure 9A, are exclusively carried out for visualization purposes. Indeed, the applied gradient algorithm, which is used to produce a seamless image, may significantly change the radiometric content in the overlapping areas; hence, it is not suitable for data analysis purposes. Looking at the temporal features at country level (Figure 9A), three main colours can be identified: blue, yellow, and light and dark orange to brown. The blue colour represents the minimum, i.e., a constant low radar backscatter during the whole year. Yellow, identified as rice and primarily located in the northeast of Bangladesh, is the combination of a strong temporal variation (red) and a high maximum (green). Light and dark orange to brown, distributed over the whole country, classified as rice, is essentially a combination of a strong temporal variation (red) with a medium maximum (green). 

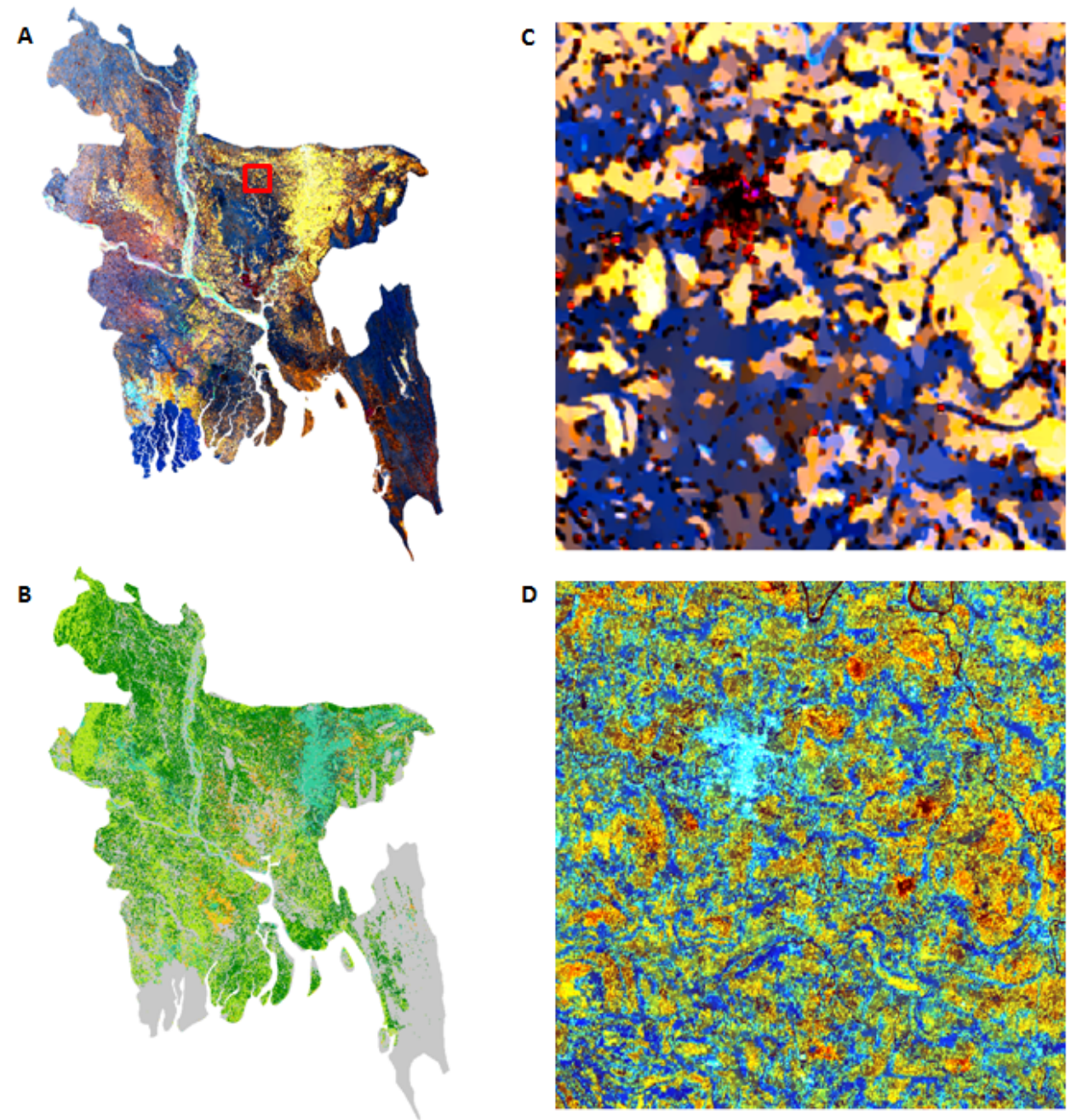

D

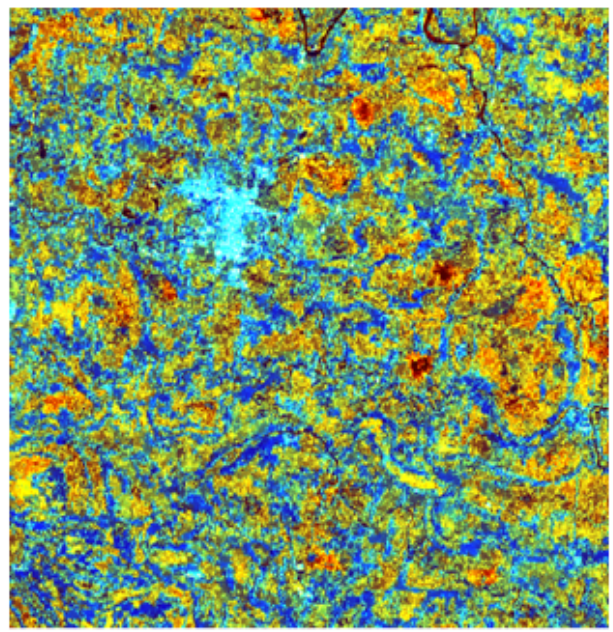

Figure 9. (A) Mosaic $(100 \mathrm{~m}$ ) of temporal features based on ENVISAT ASAR Wide Swath data acquired from 2002 to 2010. Red is the maximum variation, green is the relative maximum, and blue is the relative minimum. (B) Rice extent based on temporal features of archive ENVISAT ASAR Wide Swath data. Light green is single rice, dark green is double rice, aquamarine is rice grown after a long flooding duration (up to six months), and orange is rice mixed with other crops. (C) Enlargement of A (red box). (D) Temporal features $(15 \mathrm{~m}$ ) based on ENVISAT ASAR Alternating Polarization data acquired from June 2011 to March 2012 on the same area shown in C. Red is the maximum variation, green is the relative maximum, and blue is the relative minimum.

Due to the different acquisition times and geometry between the two orbits, the five temporal features - derived from the monthly averaged backscattering coefficient - are computed for each orbit separately. The rice extent is generated according to the rules described in section 3.1 and, subsequently, products belonging to the two orbits are shown as a mosaic at semantic 
level (Figure 9B). In this specific case, rice extent additionally includes the various rice crop seasons, which could be identified with this data set because of the good temporal frequency. Further distinction between single rice, double rice, and rice cultivated after prolonged flooding is provided by the time component-the single rice crop has a short to medium (90-120 days) duration; double rice usually means two short duration crops; and boro rice, after prolonged flooding in the northeast, is usually medium duration. This is a coarse characterisation of rice seasons, due to the fact that temporal features, derived from monthly averaged backscattering coefficient acquired irregularly, are not sufficient to follow the rapid spatial-temporal changes of agriculture. Nevertheless, this pseudo-annual data set enables the generation of a detailed rice-non-rice extent at a one-hectare scale.

With regard to the consistency of the proposed approach and to the impact of spatial resolution, temporal features derived from ASAR Wide Swath (Figure 9C) are compared to those derived from ASAR Alternating Polarization data (Figure 9D). This 15-m resolution data set has been acquired from June 2011 to March 2012 every 35 days, according to the repeat cycle of ENVISAT ASAR. The visual comparison shows that the land cover patterns, particularly of rice, are similar. It means that the multi-year (or pseudo-annual) approach is conceptually correct and viable in this case.

Another interesting observation can be made by comparing the two colour compositesspatial resolution plays an important role. Large and homogeneous regions are clearly identifiable in both acquisition modes, while small features tend to be smoothed out and to disappear. Rice covers a substantial part of the country, and although plots are small, the rice areas in much of the country are large and connected, especially in the rainy season, where rice is often the only viable crop. From analysis of SAR data at a range of resolutions (3 to 100 $\mathrm{m})$, we estimate that an accurate area estimation using this approach would need a pixel size at least five times smaller than the field size. Medium and lower spatial resolution systems should be therefore exclusively used for the provision either of extent information - a proxy of area - or, in case of agricultural applications, of phenological crop monitoring.

The ASAR Alternating Polarization HH/HV data were used to further compare the pseudoannual ASAR Wide Swath data to the quasi-annual HH/HV data, particularly with respect to the contribution of the cross-polarization for rice detection. Figure 10 (left) illustrates the temporal signatures of the ASAR WS Swath monthly averaged $\mathrm{HH}$ backscattering coefficient from January to December and those at $\mathrm{HH}$ and $\mathrm{HV}$ acquired in Alternating Polarization mode. First, this reaffirms that the use of multi-temporal data is essential, particularly at $\mathrm{HH}$ polarization. Second, the correspondence between the two $\mathrm{HH}$ radar backscatter signatures is evident, confirming the validity of the proposed approach. Third, and confirming the studies of $[12,16]$, the HV polarization contributes in the discrimination of rice from other land covers. Typically, the HH/VV ratio is preferred because it shows a variation up to $7 \mathrm{~dB}$ from the beginning of the season to the plant maturity phase [11].

Finally, the quasi-annual $\mathrm{HH} / \mathrm{HV}$ time-series is used to determine two key moments of the rice growth - start of season and peak of season (Figure 10, right). The first happens when the relative minimum is detected (September, blue colour), whereas the second is detected when the relative maximum is reached (November, green colour). A comparison with the generic 

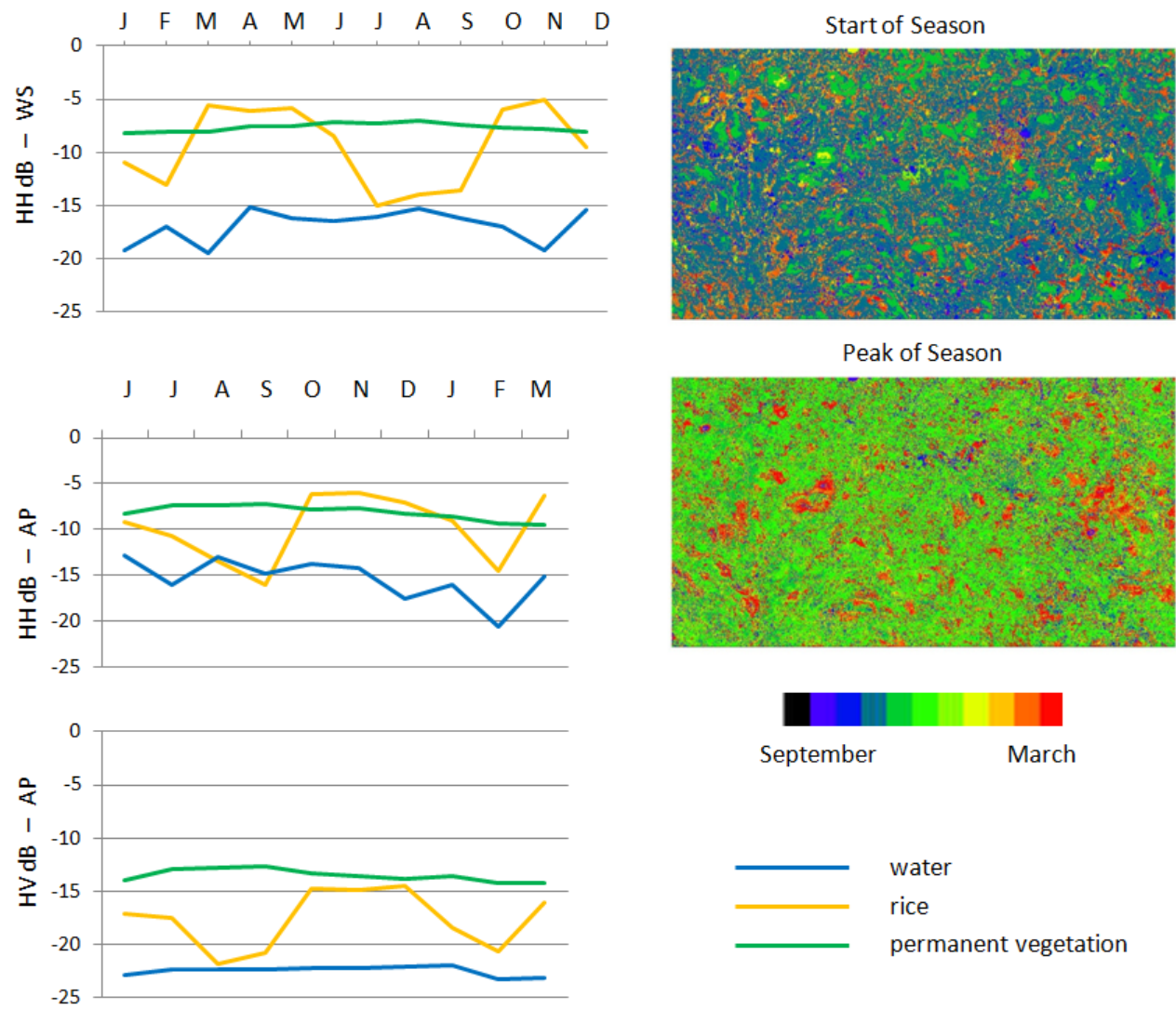

Figure 10. Top left: Temporal signatures derived from ENVISAT ASAR Wide Swath HH data acquired from 2002 to 2010. Middle left: Temporal signatures derived from ENVISAT ASAR Alternating Polarization HH data acquired from June 2011 to March 2012. Bottom left: Temporal signatures derived from ENVISAT ASAR Alternating Polarization HV data acquired from June 2011 to March 2012. Right: Detected start of season and peak of season based on ENVISAT ASAR Alternating Polarization HH data acquired from June 2011 to March 2012.

crop calendar of Figure 6 shows a good correspondence with the identified dates. However, it should be noted that a 35-day repeat cycle is not sufficient to obtain an accurate estimate of these two key moments. For this reason, the use of remote-sensing data acquired with higher temporal frequency is of advantage.

\subsection{1 seasonal rice monitoring with MODIS}

\subsubsection{Rice season map}

The number of rice seasons detected is reported in Figure 11A. For the year 2011, the analysis of optical data time-series revealed that most areas have one rice season. Two seasons were 
identified in the northern regions, while up to three seasons (red area in Figure 11A) were found in the northwest part of the country in Rajshahi Division. Areas with one or two rice seasons per year may cultivate a second or third non-rice crop, but those non-rice cropping seasons are not captured in the PhenoRice algorithm, nor is it represented in the map.

The same analysis also produces rice extent maps for the boro, aus, and aman seasons. The main rice cultivation ( $\% 49$ ) occurs in the boro period (Figure 11B), followed by aman (Figure 11D) during the wet season ( $\% 45)$. The aus crop is very small $(6 \%)$ in comparison to the other two, and occurs mainly in the central and western part of the country (Figure 11C).


Figure 11. Total detected rice seasons (A) and cultivated area for boro (B), aus (C) and aman (D) seasons.

Figure 12 reports some examples, extracted from single pixels, of temporal analysis performed by PhenoRice. The panels provide examples for single rice in boro and aman (A, B), double rice on both boro and aman $(C)$, and triple rice in all three seasons (D). As previously described, the algorithm analyses the temporal signature of three spectral indices - EVI (in green), LSWI (blue), and NDWI (light blue) - for vegetation and moisture/water. The figures also report the noise level for each composite data, mainly because of cloud contamination and are represented with grey dots, and the occurrence of the detected phenological stages. The symbols in red (square, triangle, diamond, and circle) represent agronomic flooding (MIN - crop transplanting/seeding); the plants' emergence (SoS-start of the vegetative period of rapid growth); the crop heading/flowering (MAX - start of the reproductive period); and finally, the estimated crop maturity after senescence (EoS).

Figure 12A (pixel, $24^{\circ} 17^{\prime} 54.00^{\prime \prime} \mathrm{N}-90^{\circ} 59^{\prime} 48.46^{\prime \prime} \mathrm{E}$ in the Sylhet basin in northeastern Bangladesh) shows the presence of a single rice crop in the boro season; the peculiarity of this location is (1) the strong presence of surface water for nearly six months and (2) a medium crop vegetative phase of about 120 days (period between EoS and SoS occurrence). The identification of these characteristics leads to the assumption that cultivation occurs after prolonged flooding. This observation perfectly matches the ones from the ASAR map and represents an area of low cropping intensity because of excess surface water.

In particular, Figure 12B (pixel, $22^{\circ} 1^{\prime} 30.00^{\prime \prime} \mathrm{N}-90^{\circ} 6^{\prime} 50.37^{\prime \prime} \mathrm{E}$ in Barisal Division in coastal Bangladesh) reveals a single long-duration (150 days) rice crop in the rainfed aman season 



Figure 12. Example of the temporal dynamics of the vegetation indices - EVI (green line), LSWI+0.05 (blue line), and NDWI (light-blue line), and phenological detection for MIN, SoS, MAX, and EoS. Panels A, B, C, and D show a single season for boro rice, a single season for aman rice, a double season (boro-aman), and a triple season (boro-aus-aman), respectively.

with (1) crop heading (MAX) occurring in November in the fourth quarter of the analysed season, (2) a transplanting period (MIN) in June, (3) a green-up (SoS) in July, and (4) a crop maturity (EoS) in December. This area is highly saline in the dry boro season and no cultivation is possible so the land is left fallow for much of the year, until freshwater availability from rivers or canals increase after the monsoon rains. Thus, this is another example of environmental conditions limiting cropping intensity. The agronomic flooding from May to August that precedes the crop greening is particularly clear from the interpretation of LWSI and NDWI indices trends. The former, as described by Xiao et al. (2005), shows values far greater than EVI, whereas the latter presents values greater than zero.

Figure $12 \mathrm{C}$ (pixel, $25^{\circ} 10^{\prime} 60.00^{\prime \prime} \mathrm{N}-89^{\circ} 14^{\prime} 42.64^{\prime \prime} \mathrm{E}$ in Ranjpur Division, northwestern Bangladesh) shows the detection of two rice crops in 2011. The first boro crop occurs during the first and second quarters, from February to June, with crop heading in late March; whereas, the second one, aman rice, takes place in the third and fourth quarters, starting in July and finishing in late October. The boro crop is a short-duration one, 90 to 100 days, whereas the aman rainfed crop is much longer, 130-150 days.

Finally, Figure 12D (pixel $24^{\circ} 36^{\prime} 45.00^{\prime \prime} \mathrm{N}-8^{\circ} 24^{\prime} 6.25^{\prime \prime} \mathrm{E}$, Rajshahi Division in central Bangladesh) illustrates the case of three rice seasons, heading occurrences are in February (boro), July (aus), and October (aman), respectively. In this case, it is possible to appreciate that the crop durations are much shorter than the ones in the previous examples - they are all 90 to 110 days - and could represent short-duration, high-yielding varieties that have done much to increase rice productivity in Bangladesh since the Green Revolution. 


\subsubsection{Phenological detection maps}

Figure 13 shows the phenological detection results for the year 2011. The data represent a spatial analysis conducted at sub-district or thana level, taking into account the median value of the different phenological data occurring within each sub-district. Pixel-level interpretation and visualisation is challenging because of the inability of the algorithm to detect every occurrence, the well-known low-resolution bias of MODIS data when observing fields, and the heterogeneity of the cropping systems [27]. Thus, given that PhenoRice is a very conservative approach to detection (in order to minimize false positive error) and, if we accept that PhenoRice can only capture a proportion of the phenomena understudy, this aggregation of data around a median value gives a more robust interpretation of the phenology data for a selected unit of analysis. Furthermore, we excluded sub-districts if there were fewer than 30 pixels detected for a given season.

The boro maps confirm the well-known patterns of agronomic practices. Fields start to be flooded (MIN boro map) in the southeast, red (Jan 2011), and then the season progresses northwest, orange (Feb 2011). The SoS boro map highlights this trend more clearly. On the other hand, the aman season starts in the north and heads south due to the north-south progression of freshwater in the river systems as depicted by the light green (Jun 2011) and green (Jul-Aug 2011) colours in the MIN map, respectively.

During the boro season, no rice crop is detected in the southwest since that corresponds to the dry season, where there is insufficient freshwater for irrigation and the region is exposed to high water salinity. Freshwater availability increases in the aman season in the southwest during that time. The correct detection of these two seasons in this part of the country suggests that this approach is well suited to the detection of seasonality.

The analysis of the aus map is more difficult because of the smaller and more fragmented area of the rice crop in this season. Aus rice detection is concentrated mainly in the central part of Bangladesh, along the Ganges River, and on the eastern region of Chittagong. The aus crop relies on both early-season irrigation and late-season rainfall, and this partially explains the limited extent. Two cropping patterns could appear: the first one, much earlier in the middle of the country, and the second, a later pattern for the rest of the country.

\section{Discussion}

\subsection{Observations on the SAR analysis and results}

Temporal analysis of moderate-resolution SAR, especially using the backscattering coefficient $\left(\sigma^{\circ}\right)$ from C-band time-series, is ideally suited for irrigated and lowland rice detection. It is particularly advantageous in monsoon Asia where much of the world's rice is produced over huge areas and under cloudy conditions.

The use of the 10-year ENVISAT ASAR Wide Swath data archive, even if not optimal for the targeted application - since it is irregularly acquired in temporal terms - provides a valuable 
BORO

2010-2011
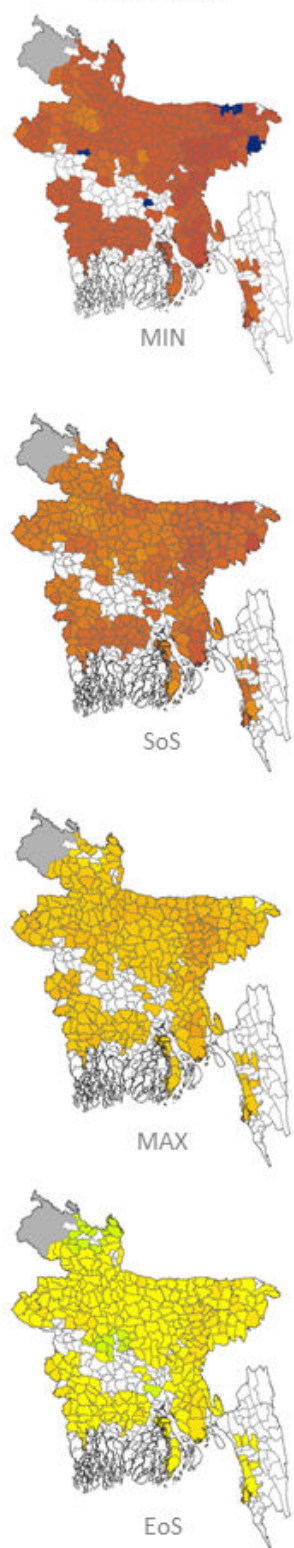

AUS

2011


AMAN

2011

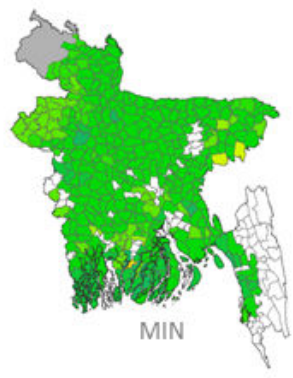

Jan 01-15

Jan 15-30

Feb 01-15

Feb 15-30

Mar 01-15

Mar 15-30

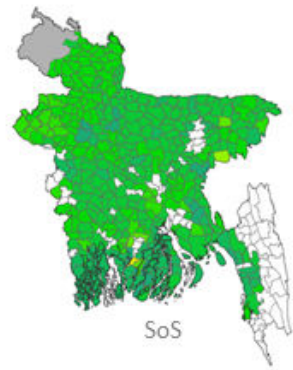

Apr 01-15

Apr 15-30

May 01-15

May 15-30

Jun 01-15

Jun 15-30

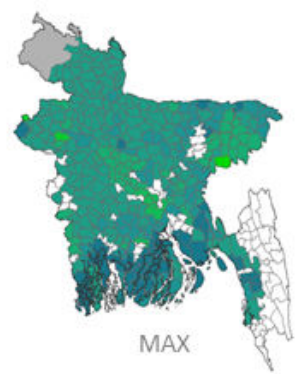

Jul 01-15

Jul 15-30

Aug 01-15

Aug 15-30

Sep 01-15

Sep 15-30

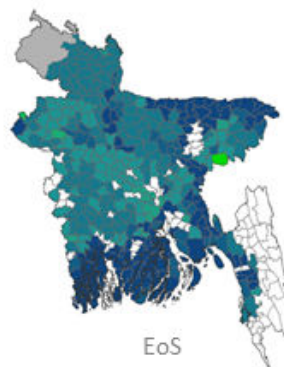

Oct 01-15

Oct 15-30

Nov 01-15

Nov 15-30

Dec 01-15

Dec 15-30

Figure 13. From top to bottom: Min, SoS, Max, and EoS phenological metrics for the boro, aus, and aman rice seasons in Bangladesh, in the analysed time window: June 2010-December 2011. 
data source, enabling the generation of a consistent rice extent product, with 1-hectare resolution, nationally. In this respect, it is well-known that SAR data availability is currently problematic, mainly because of the recent failure of the ENVISAT ASAR and ALOS PALSAR-1 systems. Nevertheless, today, there are tens of thousands of archived unexploited SAR images that could be leveraged for baseline mapping to generate rice extent and area. This multi-year approach is applicable to Asia because most rice systems are generally not subject to seasonal rotations (upland rice is one exception, but it accounts for a small portion of the total rice area) and there is little scope for rice area expansion in Asia. This is obviously not feasible for all crops, where rotation mandatory and significant land-use change can occur.

The availability of systematic SAR acquisitions at an appropriate time interval - for instance, bi-monthly or weekly, as planned for in the Sentinel-1A/B mission - would allow the generation of annual and seasonal rice area data nationally. Moreover, high-resolution SAR time-series acquired along the whole season could complement the phenological monitoring provided by optical moderate resolution, particularly with respect to the detection of key phenological stages such as the start and peak of season. This would be facilitated if space agencies, with mandates for future SAR missions, could incorporate systematic background missions according to the geographical areas and applications, instead of building data archives based on sporadic/irregular acquisitions.

Concerning the SAR data processing aspect, it is essential that a multi-temporal data processing approach is performed, in primis, to enhance the data quality - hence, the level of detail - by significantly reducing the speckle. Future hyper-temporal data stacks acquired from Sentinel-1A/B will have an important role for the provision of high-quality data (i.e., high Equivalent Number of Looks) at the highest level of detail. This will permit a pixel-based approach, which is simpler and less time-consuming than a regional based one.

Due to the nature of the multi-year ENVISAT ASAR Wide Swath data (irregularly acquired in temporal terms), the resulting rice temporal signature is occasionally not optimal or not representative enough for rigorous date-by-date analysis. For this reason, we used a pixel-wise temporal signature analysis using selected representative temporal features (relative minimum and maximum, and the corresponding difference, minimum and maximum gradient between two subsequent acquisitions). Although this approach discriminated between rice and non-rice areas, the features are not sufficient to properly determine the country-wide extent of various rice seasons (single, double, etc.) and, even less, the rice phenology. There are some exceptional cases with sufficient coverage, where various rice seasons can be identified by detecting the amount of minimum and maximum gradients and related dates. In summary, assuming the availability of dense multi-year, regularly acquired SAR images, an average rice crop calendar could be generated together with the rice extent.

\subsection{Observations on the MODIS analysis and results}

Temporal analysis of moderate-resolution optical data time-series for detection of rice phenology is possible where there is a good rice extent base map from SAR or other sources, and good prior knowledge of the general cropping systems. Phenological occurrence maps show an agreement with local knowledge on rice cultivation, highlighting different gradients 
of transplanting dates in the country. Analysis and interpretation of Vegetation Index timeseries without prior knowledge or understanding of the crops, cropping patterns, and crop management is extremely challenging and difficult to interpret in terms of an operational crop monitoring system.

The proposed method is able to identify particular crop management systems such as single-, double-, and triple-cropping patterns. Moreover, a range of seasonalities and of crop durations from 90-to 150-day varieties could be detected. Further experiments in rice/wheat, rice/pulse, rice/shrimp and drought-prone areas should be conducted to assess the capability of detection in other commonly occurring rice cropping systems and environments.

The optical time-series data described the temporal pattern of rice systems across Bangladesh. The SAR data describes where rice is cultivated and the optical data describes when rice is cultivated. This is encouraging considering the aforementioned triple challenges of using moderate-resolution data in a region characterised by pervasive cloud cover, small fields, and complex cropping systems. The conservative nature of the phenological detection with moderate-resolution data suggests that pixel-level interpretation and pixel counting for area estimation should be avoided as they are likely to be unreliable estimates of crop system characteristics. Such estimates can always be improved through fine-tuning, expert classification, and other manual interventions, but these do not lend themselves to operational methods that require rapid and robust estimates that are free of user-bias.

Summarising the crop phenology at high levels of aggregation that match existing data or management units could provide one solution to this underestimation effect. PhenoRice is conservative in its detection criteria and, if we can assume that the detected pixels are representative of the cropping systems, then some statistical representation of the seasonality by sub-district, irrigation scheme, or other management unit would provide useful information. Most cropping calendars (e.g. Figure 2) provide ranges for the start and end of season, and remotely sensed phenolology metrics could be used in the same way to provide robust, yearand season-specific information to assess the onset of a late or early season. The same information is vital for yield modelling, since the phenology data can be used to drive/force crop growth simulation models in order to produce more reliable yield estimates.

\subsection{Final comments}

The current structure of the algorithm does not allow a near-real-time analysis since it needs to obtain all remote-sensing data through to the end of the year to provide complete phenological information. This can be overcome by interpreting the vegetation indexes or $\sigma^{\circ}$ trends at the end of the time-series, which would be refined as new information is added in nearreal-time. Thus, for each phenological parameter, there would be a 'possible detection' counterpart that could be provided rapidly and which would be confirmed as a 'real detection' after several more images are acquired. This approach to crop and crop phenology detection is an analogy to what can be achieved with the advent of the Landsat continuity mission and GMES-ESA Sentinel mission, which will, for the first time, provide the possibility of highresolution SAR and multi-spectral time-series analysis with weekly revisit periods. Moderate- 
resolution analysis will still play a role with Proba V, representing an alternative or a complement, to MODIS data.

In this processing chain, we have demonstrated the joint use of active and passive data as a smart method, based on the strengths of both sensors, to produce rice extent information (from multi-year ASAR analysis) and seasonal monitoring (from MODIS analysis). Crop monitoring systems should rely on a range of remote-sensing information sources in order to obtain the best possible information and smart combinations. The ever-increasing range of information from remote sensing is essential if such systems are to become operational, reliable, and accurate.

\section{Acknowledgements}

This work has been undertaken within the framework of the Remote Sensing-Based Information and Insurance for Crops in emerging Economies (RIICE) project financially supported by the Swiss Development Cooperation. It was also funded by the CGIAR Global Rice Science Partnership (GRiSP) programme. We are grateful to the European Space Agency for access to the archive of ENVISAT ASAR data.

\section{Author details}

Andrew Nelson ${ }^{1 *}$, Mirco Boschetti ${ }^{2}$, Giacinto Manfron², Franceco Holecz ${ }^{3}$, Francesco Collivignarelli ${ }^{3}$, Luca Gatti ${ }^{3}$, Massimo Barbieri ${ }^{3}$, Lorena Villano ${ }^{1}$, Parvesh Chandna ${ }^{4}$ and Tri Setiyono ${ }^{1}$

*Address all correspondence to: a.nelson@irri.org

1 IRRI, Los Baños, Philippines

2 CNR, Milano, Italy

3 Sarmap, Purasca, Switzerland

4 IRRI, Dhaka, Bangladesh

\section{References}

[1] National Food Supply data from the Crops Primary Equivalent table. FAOSTAT. http://faostat.fao.org/site/609/defalt.aspx\#ancor. (accessed 01-Nov-2013). 
[2] Yearbook of Agricultural Statistics of Bangladesh. Bangladesh Bureau of Statistics. http://bbs.gov.bd/PageWebMenuContent.aspx?MenuKey=314. (accessed 01Nov-2013).

[3] Estimates of Boro, Aus and Aman rice. Bangladesh Bureau of Statistics. http:// bbs.gov.bd/PageWebMenuContent.aspx?MenuKey=144. (accessed 01-Nov-2013).

[4] Hussain SG., Iqbal A. editors. Research Priorities in Bangladesh Agriculture. Bangladesh Agricultural Research Council. Dhaka, Bangladesh. 2011.

[5] Kam SP., Holecz F., van Valkengoed E., Barbieri M., Casiwan CB., Asilo SL., Santos LA., Manalili RG., Collado WB., Adriano SA., Maunahan A. The makings of an internet-based rice information system: Piloting in the Philippines, First Symposium on Geoinformatics, Philippines. 2004.

[6] Xiao X., Boles S., Frolking S., Li C., Babu JY., Salas W., Moore III, B. Mapping paddy rice agriculture in South and Southeast Asia using multi-temporal MODIS images. Remote Sensing of Environment, 2006;100, 95-113.

[7] Manfron G., Crema A., Boschetti M., Confalonieri R., 2012. Testing automatic procedures to map rice area and detect phenological crop information exploiting time series analysis of remote sensed MODIS data. Proc. SPIE 8531, Remote Sensing for Agriculture, Ecosystems, and Hydrology XIV, 85311E (October 19, 2012); doi: 10.1117/12.974662. 8531, 85311E-85311E-11.

[8] Holecz F., Collivignarelli F., Barbieri M., 2013. Estimation of cultivated area in small plot agriculture in Africa for food security purposes, ESA Living Planet Symposium, Edinburgh. 09-13 September, 2013.

[9] Holecz F., Barbieri M., Collivignarelli F., Gatti L., Nelson A., Setiyono TD., Boschetti M., Manfron G., Brivio PA., Quilang E., Obico M., Minh VQ., Kieu DP., Huu QN., Veasna T., Intrman A., Wahyunto P., and Pazhanivelan S. An operational remote sensing based service for rice production estimation at national scale. ESA Living Planet Symposium, Edinburgh. 09-13 September, 2013.

[10] Ulaby FT., Allen CT., Eger G., Kanemasu ET. Relating the microwave backscattering coefficient to leaf area index. Remote Sensing of Environment, 1984;14 113-133.

[11] Le Toan T. Laur H. Multitemporal and dual polarisation observations of agricultural crops by X-band SAR images, Geoscience and Remote Sensing Symposium, IGARSS'88, pp. 1291-1294. 12-16 September 1988.

[12] Inoue Y., Kurosu T., Maeno M., Uratsuka V., Kozu T., Dabrowka-Zielinska K., Qi J. Season-long daily measurements of multifrequency (Ka, Ku, X, C, and L) andfull-polarization backscatter signatures over paddy rice field and their relationship with biological variables. Remote Sensing of Environment 2002;81(3) 194-204. 
[13] Suga Y., Konishi T. Rice crop monitoring using X-, C-and L-band SAR data. Proc. SPIE 7104, Remote Sensing for Agriculture, Ecosystems, and Hydrology X, 710410 (October 02, 2008); doi:10.1117/12.800051.

[14] Bouvet A., Le Toan T., Lam-Dao N. Monitoring of the rice cropping system in the Mekong Delta using ENVISAT/ASAR dual polarization data. IEEE Transactions of Geoscience and Remote Sensing, 2009;47(2) 517-526.

[15] Oh Y., Kim Y., Hong JY., Kim YH. Polarimetric Backscattering Coefficients of FloodedRice Fields at L-and C-Bands: Measurements,Modeling, and Data Analysis.IEEE Transactions on Geoscience and Remote Sensing, 2009; 47(8) 2714-2720.

[16] Kim YH., Hong SY., Lee YH. Estimation of paddy rice growth parameters using L, C, X-bands polarimetric scatterometer. Korean Journal of Remote Sensing, 2009;25(1) 31-44.

[17] Kim S., Kim B., Kong Y., Kim YS. Radar backscattering measurements of rice crop using X-band scatterometer. IEEE Transactions on Geoscience and Remote Sensing, 2000;38(3) 1467-1471.

[18] de Grandi F., Leysen M., Lee J., Schuler, D. Radar reflectivity estimation using multiplicative SAR scenes of the same target: technique and applications. Geoscience and Remote Sensing Symposium, IGARSS'97. 3-8 August 1997

[19] Aspert F., Bach-Cuadra M., Cantone A., Holecz F., Thiran J-P. Time-varying segmentation for mapping of land cover changes. ESA ENVISAT Symposium, Montreux, Switzerland. April 23-27 2007.

[20] Boschetti M., Stroppiana D., Brivio PA., Bocchi S. Multi-year monitoring of rice crop phenology through time series analysis of MODIS images. International Journal of Remote Sensing. 2009;30, 4643-4662.

[21] Boschetti M., Nelson A., Manfron G., Brivio PA. An automatic approach for rice mapping in temperate region using time series of MODIS imageryø: first results for Mediterranean environment, in: European Geophysical Union (Ed.), EGU Geophysical Research Abstracts. 14068-1. 2012.

[22] Xiao X., Boles S., Liu J., Zhuang D., Frolking S., Li C., Salas W., Moore B. Mapping paddy rice agriculture in southern China using multi-temporal MODIS images. Remote Sensing of Environment 2005;95 480-492.

[23] Peng D., Huete AR., Huang J., Wang F., Sun H. Detection and estimation of mixed paddy rice cropping patterns with MODIS data. International Journal of Applied Earth Observation and Geoinformation. 2001;13 13-23.

[24] Rogers AS., Kearney MS. Reducing signature variability in unmixing coastal marsh Thematic Mapper scenes using spectral indices. International Journal of Remote Sensing 2004;25 2317-2335. 
[25] Huete A., Didan K., Miura T., Rodriguez EP., Gao X., Ferreira LG. Overview of the radiometric and biophysical performance of the MODIS vegetation indices. Remote Sensing of Environment 2002;83, 195-213.

[26] Chen J., Jönsson P., Tamura M., Gu Z., Matsushita B., Eklundh L. A simple method for reconstructing a high-quality NDVI time-series data set based on the SavitzkyGolay filter. Remote Sensing of Environment 2004;91, 332-344.

[27] Boschetti L., Flasse SP., Brivio PA. Analysis of the conflict between omission and commission in low spatial resolution dichotomic thematic products: The Pareto Boundary. Remote Sensing of Environment 2004;91, 280-292. 
